05

\title{
Особенности механического поведения силовых приводов кольцевой формы, действующих в режиме обратимой памяти формы
}

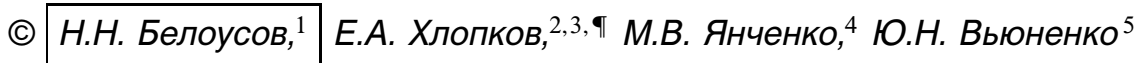 \\ ${ }^{1}$ Донецкий фризико-технический институт им. А.А. Галкина, \\ 83114 Донецк, Украина \\ ${ }^{2}$ Санкт-Петербургский политехнический университет Петра Великого, \\ 194021 Санкт-Петербург, Россия \\ ${ }^{3}$ Новгородский государственный университет им. Ярослава Мудрого, \\ 173003 Великий Новгород, Россия \\ ${ }^{4}$ ООО „Мидетол“, \\ 196655 Санкт-Петербург, Россия \\ ${ }^{5}$ ООО „ОПТИМИКСТ ЛТД“, \\ 195426 Санкт-Петербург, Россия \\ ฯ e-mail: hlopkovelisey@mail.ru
}

Поступило в Редакцию 24 октября 2019 г.

В окончательной редакции 22 августа 2020 г.

Принято к публикации 7 сентября 2020 г.

Исследована возможность повышения деформационно-силовых свойств кольцевых приводов из никелида титана, действующих в режиме обратимой (двусторонней) памяти формы (ОПФ). В этих целях использовано термоциклирование овального образца с переводом материала из низкотемпературной мартенситной фазы в высокотемпературную аустенитную в свободном состоянии и охлаждения через температурный интервал превращения под нагрузкой. Показана возможность генерации силы в кольцевых конструкциях, формоизменение которых обусловлено процессом ОПФ, как во время нагрева, так и при охлаждении. Представлены данные о несимметричности этих свойств в отношении направления изменения температуры. Показано значительное влияние скорости охлаждения на деформационно-силовые свойства кольцевых конструкций приводов.

Ключевые слова: никелид титана, термоциклирование, ОПФ, мартенситная и аустенитная фазы, термоцикл.

DOI: 10.21883/JTF.2021.02.50360.353-19

\section{Введение}

Возможности кольцевых силовых пучковых элементов (КСПЭ, „металлические мышцы“) как специальных приводов, действующих в результате развития в металле механизмов эффекта памяти формы (ЭПФ), приведены в работе [1]. Изготовленные из никелида титана, такие „металлические мышцы“ показали свою эффективность в технологии производства слоистых материалов, работая в миниатюрных прессах конструкции ШеР. Изучение влияния масштабного фактора на возможности КСПЭ показало, что приводы из сплава TiNi могут работать не только в режиме реализации ЭПФ, но и в режиме обратимой (или двусторонней) памяти формы (ОПФ) [2]. Это свойство, присущее сплавам, претерпевающим мартенситные термоупругие превращения, исследуют более полувека [3]. Наиболее активно изучение ОПФ стали проводить в последние десятилетия из-за предполагаемого использования этого физического явления в робототехнике и медицине [4-10]. В этих исследованиях было показано, что деформационные характеристики ОПФ можно наращивать за счет многократного сочетания формоизменения образцов в низкотемпературном состо- янии и термоциклирования с переводом материала конструкции из мартенситной фазы в аустенитную и обратно. В работе [5] показано, что при активном деформировании образца на $4.8 \%$ в низкотемпературном состоянии ОПФ после 10 тренировочных циклов термомеханического воздействия равна $\sim 0.3 \%$, а после 80 циклов достигает $\sim 2.5 \%$ деформации. Однако у такой технологии термомеханической обработки материала, повышающей ОПФ, имеется альтернатива. Стимулирования деформационных процессов ЭПФ и ОПФ можно добиться за счет использования состояния пластичности превращения, наблюдаемого у материалов данного класса [3]. В этом случае образец из сплава с термоупругим фазовым превращением охлаждается под нагрузкой через интервал температур прямого мартенситного превращения. Из-за значительного снижения предела упругости и „дефекта“ упругих модулей материала [11] в области температур перестройки кристаллической решетки под воздействием внешней силы накапливается необратимая деформация изделия. Полученное таким образом формоизменение в последующем восстанавливается при нагреве в результате ЭПФ. А дальнейшее термоциклиро- 
вание показывает, что накопленная во время остывания образца деформация частично обеспечивает и действие эффекта ОПФ. Авторами работы [12] была сделана попытка использовать такую технологию для повышения деформационных характеристик ОПФ, однако полученные результаты показали, что после 10 термоциклов под нагрузкой изменение геометрических размеров образца за счет ОПФ больше, чем после 20. Измерение характеристик ОПФ проводили во время нагрева и охлаждения в свободном состоянии по окончанию тренировочных теплосмен. Поскольку в работе [12] силовое воздействие на образец осуществлялось как на стадии охлаждения, так и на стадии нагрева, в данной работе была изучена возможность наращивания деформационного эффекта в КСПЭ при ОПФ за счет их многократного охлаждения под нагрузкой через интервал температур прямого мартенситного превращения. При этом нагрев кольца проводили в свободном состоянии.

\section{1. Проведение исследований}

Деформационные процессы, обусловленные мартенситными превращениями, изучали на овальном образце, изначально представляющим окружность диаметром $\sim 62 \mathrm{~mm}$. Кольцо было сварено из проволоки диаметром $2 \mathrm{~mm}$, полученной из сплава TiNi 50.4 at.\%. Масса
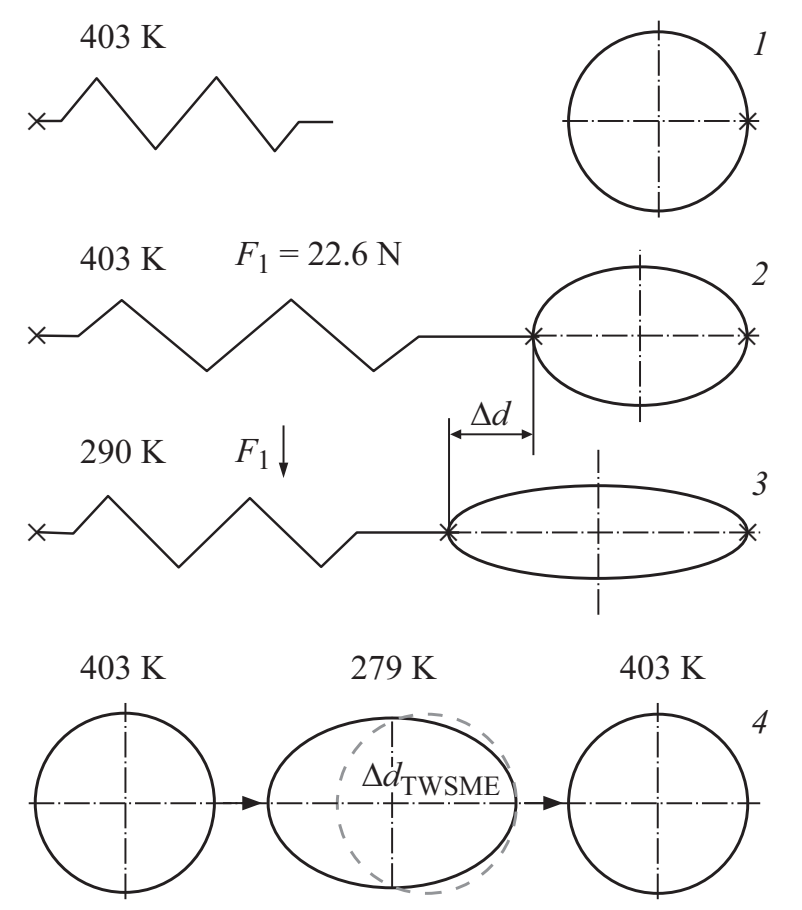

Рис. 1. Схема повышения обратимой памяти формы КСПЭ: 1 - КСПЭ до нагружения, $2-$ КСПЭ в момент нагружения в аустенитном состоянии, $3-$ КСПЭ после деформации пластичности прямого превращения, $4-$ реализация обратимой памяти формы КСПЭ, $\Delta d-$ формоизменение размера КСПЭ в результате пластичности превращения, $\Delta d_{\mathrm{TWSME}}-$ изменение размера КСПЭ во время развития эффекта ОПФ, $F_{1}-$ сила взаимодействия КСПЭ с пружиной.

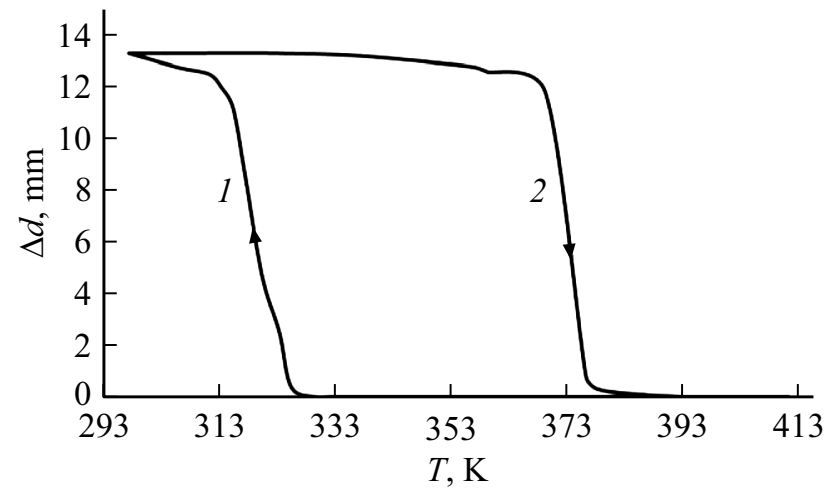

Рис. 2. Температурная зависимость формоизменения сварного кольца в результате пластичности превращения (1) и ЭПФ (2) в первом тренировочном цикле.

кольцевого силового элемента равнялась $\sim 5$ g. На рис. 1 приведена схема тренировки овального силового элемента. Для деформирования кольца из никелида титана использовали спиральную пружину. Нагрев пружины и овала до $403 \mathrm{~K}$ проводили в свободном состоянии (рис. 1,1$)$. Предварительные исследования данного сплава показали, что при максимальной температуре цикла сплав гарантированно находится в аустенитном состоянии. В этих условиях упругую спираль растягивали и соединяли с овалом. Сила взаимодействия пружины с кольцом $F_{1}$ равнялась $22.6 \mathrm{~N}$. Диаметр вдоль направления действия силы увеличивался на $\sim 1 \mathrm{~mm}$ (рис. 1,2 ). В таком состоянии система кольцо-пружина охлаждалась с термостатом. При температуре $\sim 328 \mathrm{~K}$ отметили начало деформирования образца (рис. 2, кривая 1). Постепенно овал приобретал эллипсоподобную форму (рис. 1,3). Кольцо вдоль направления действия силы при температуре $303 \mathrm{~K}$ было вытянуто на $\Delta d=13 \mathrm{~mm}$, а $F_{1}$ уменьшилась до $\sim 15.6 \mathrm{~N}$. При комнатной температуре образец разгрузили и во время повторного нагрева наблюдали за развитием ЭПФ в интервале температур от 363 до $378 \mathrm{~K}$ (рис. 2, кривая 2). Начальная форма окружности была восстановлена полностью. Затем во время охлаждения была определена величина формоизменения $\Delta d_{\text {TWSME }}$, обусловленная обратимой памятью формы. Она оказалась равной $2.2 \mathrm{~mm}$. Третий нагрев восстановил начальное состояние овала. В аустенитном состоянии образец был вновь нагружен. Таким образом, в течение десяти термоциклов формоизменение кольца под нагрузкой при охлаждении сменяло восстановление контура окружности при нагреве в свободном состоянии. Постепенно от цикла к циклу нарастала величина $\Delta d$. Охлаждение в 11-м термоцикле привело к повышению ее до $15 \mathrm{~mm}$. В 12-м термоцикле охлаждение образца без нагрузки показало, что характеристика ОПФ $\Delta d_{\text {TWSME }}$ возросла более чем в 3 раза (рис. 3, кривая 1). Кривая 2 демонстрирует развитие деформационного процесса ОПФ при нагреве в этом же цикле. Обращает на себя внимание изменение температурных интервалов 


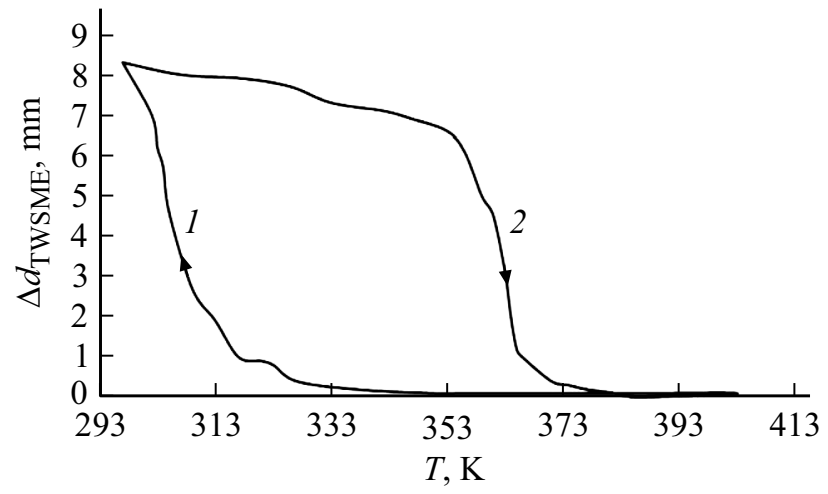

Рис. 3. Температурная зависимость формоизменения сварного кольца в результате ОПФ после 12 термоциклов при охлаждении (1) и нагреве (2).

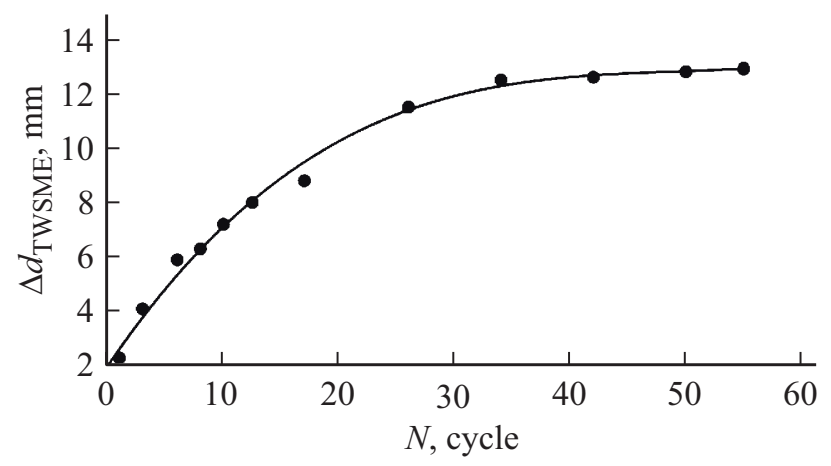

Рис. 4. Зависимость формоизменения обратимой памяти формы КСПЭ от числа циклов.

формоизменения в сравнении с рис. 2. Деформационные эффекты, обусловленные пластичностью превращения и памятью формы, начинаются при более высоких температурах.
Дальнейшее термоциклирование образца с нагревом в свободном состоянии и охлаждением под нагрузкой показало, что нарастание $\Delta d_{\text {TWSME }}$ до 35-го цикла шло достаточно быстро. Затем в течение 20 термоциклов прирост $\Delta d_{\text {TWSME }}$ от цикла к циклу стал снижаться. К 60-му термоциклу величина $\Delta d_{\text {TWSME }}$ стабилизировалась (рис. 4), достигнув значения $12.5 \mathrm{~mm}$.

После 65 термоцикла охлаждение под нагрузкой не проводили. Формоизменение овала при охлаждении и при нагреве проходило вследствие развития процесса обратимой памяти формы. К 85 термоциклу величина $\Delta d$ TWSME уменьшилась до $10 \mathrm{~mm}$ и во время следующих 50 теплосмен не менялась.

Наличие силового противодействия деформационным процессам ОПФ (рис. 5,a) уменьшило величину $\Delta d_{\text {TWSME }}$ до $\sim 8.3 \mathrm{~mm}$ (рис. 6, кривая 1). При нагреве усилие, имеющее начальную величину $\sim 6.2 \mathrm{~N}$ и направленное вдоль максимального диаметра овала, нарастало из-за стремления овала восстановить форму окружности при переходе образца в высокотемпературное состояние. В этом эксперименте положение спиральной пружины относительно овала соответствовало рис. 5, $a, 1$. Во время нагрева и развития ОПФ силовое воздействие на овал возрастало (рис. 5, a, 2). При $393 \mathrm{~K}$ изменение геометрических параметров образца остановилось. Величина $F_{1}$ достигла $10.2 \mathrm{~N}$.

Во время охлаждения противодействующая сила в большей степени препятствует деформационным процессам ОПФ. В высокотемпературном состоянии силовое взаимодействие образца с пружиной в начале охлаждения отсутствовало (рис. $5, b, 1)$. В момент старта деформационного процесса при достижении $335 \mathrm{~K}$ пружина растягивалась и оказывала силовое воздействие на овал (рис. 6, кривая 2), препятствуя изменению его геометрических параметров. Это снизило деформационный эффект ОПФ до $4.3 \mathrm{~mm}$. Силовой элемент развил усилие $\sim 5.9 \mathrm{~N}$, т.е. возможности силовых элементов,
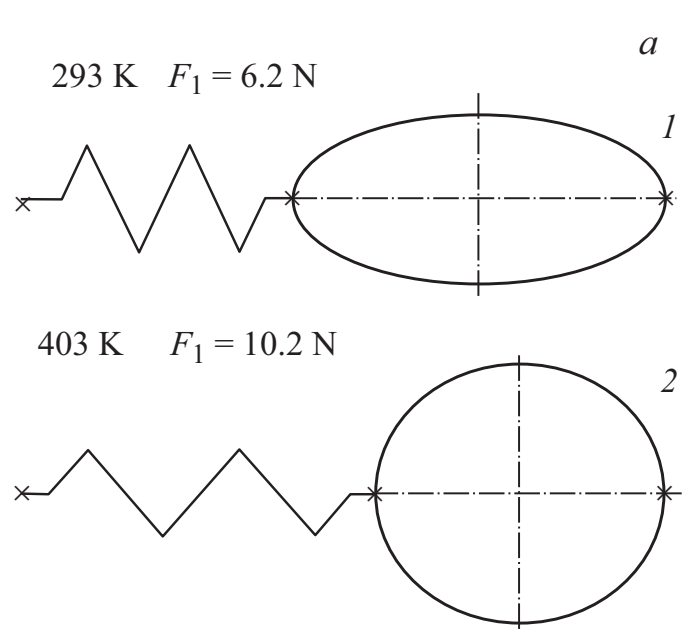

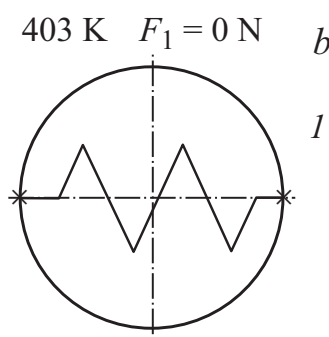

$293 \mathrm{~K} \quad F_{1}=5.9 \mathrm{~N} 2$

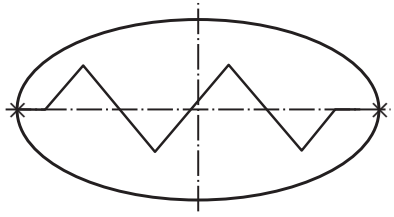

Рис. 5. Схема реализации обратимой памяти формы с генерацией силы: $a-$ при нагреве, $b-$ при охлаждении; $1-$ начальное состояние КСПЭ, 2 - формоизменение размера КСПЭ во время развития эффекта ОПФ. 


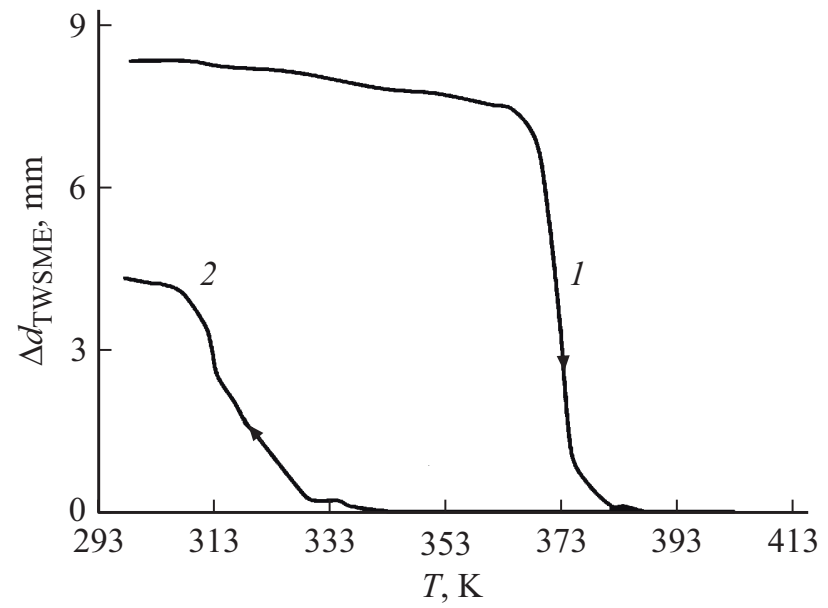

Рис. 6. Развитие деформационных процессов ОПФ КСПЭ в присутствии противодействующих сил при нагреве (1) и охлаждении (2).

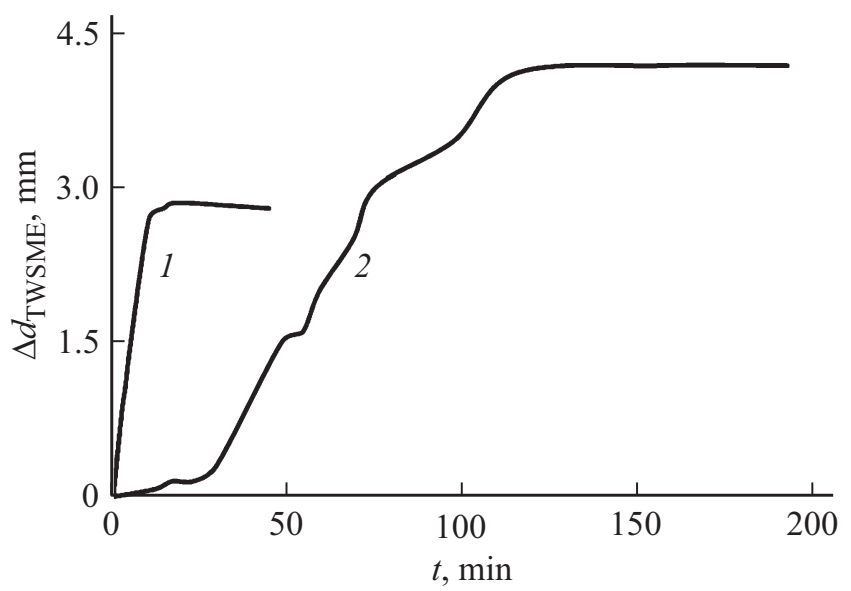

Рис. 7. Развитие деформационных процессов ОПФ КСПЭ в присутствии противодействующих сил при скорости охлаждения $\sim 2(1)$ и $\sim 0.3 \mathrm{~K} / \mathrm{min}(2)$.

работающих в режиме обратимой памяти формы, не симметричны в отношении направления изменения температуры. При нагреве деформационно-силовые свойства овальных образцов из никелида титана заметно выше соответствующих характеристик при охлаждении.

Заметное влияние на деформационно-силовые характеристики КСПЭ, действующего в режиме ОПФ, может оказывать и скорость охлаждения образца. На рис. 7 приведены кривые изменения во времени $\Delta d_{\text {TWSME }}$ овала, охлаждаемого со скоростью $\sim 2 \mathrm{~K} / \mathrm{min}$ (кривая 1 ) и $\sim 0.3 \mathrm{~K} / \mathrm{min}$ (кривая 2). Рост скорости изменения температуры приводит к уменьшению $\Delta d$ TWSME в 1.4 раза. При этом генерируемая сила также снижается с 5.9 до $4.2 \mathrm{~N}$. Подобную зависимость от скорости охлаждения наблюдали при изменении деформации пластичности превращения [13]. Анализ температурных полей в работе [13] показал, что малая скорость охлаждения синхронизирует перестройку кристаллической решетки по всему объему конструкции. Стадия развития деформаций ОПФ при охлаждении совпадает с температурным интервалом роста модуля упругости [3]. Поскольку повышение упругих характеристик следует за стадией их понижения в начале прямого фазового превращения (рис. 3) формоизменение наблюдается при более низких температурах относительно деформационных процессов пластичности превращения (рис. 2). По-видимому, две эти причины (синхронизация фазового перехода по объему силового элемента и нарастание величин упругих характеристик) способствуют росту деформационносиловых возможностей кольцевых приводов при малых скоростях охлаждения. Повышение скорости охлаждения овала, как показано в [13], усиливает неоднородность распределения температуры вдоль радиуса сечения проволоки. Поэтому трансформация кристаллической решетки при мартенситном превращении в проволоке развивается постепенно, от поверхности к ее центру. Это рассогласование фазового превращения по объему приводит к снижению показателей функциональных возможностей силового элемента, действующего в режиме развития ОПФ на стадии охлаждения.

\section{Заключение}

Таким образом, приведенные сведения показывают возможности конструкционного решения в создании силовых элементов и приводов из материалов с ЭПФ, действующих в режиме обратимой (двусторонней) памяти формы. Усиливать деформационно-силовые свойства кольцевых силовых элементов возможно за счет их термоциклирования с переводом материала конструкции из мартенситного состояния в аустенитное и обратно, при этом нагрев образцов проводится в свободном состоянии с развитием формоизменения за счет ЭПФ. Во время охлаждения конструкция находится под внешней нагрузкой, задающей соответствующее формоизменение вблизи температур прямого мартенситного перехода, когда материал находится в состоянии пластичности превращения. Такое воздействие на материал конструкции позволяет увеличить показатели пластичности превращения, обратимой памяти формы и генерируемых сил, причем не только на стадии нагрева, но и на стадии охлаждения.

Отметим, что при проведении технологических операций с силовыми элементами надо учитывать влияние скорости охлаждения на их деформационно-силовые характеристики.

\section{Конфликт интересов}

Авторы заявляют, что у них нет конфликта интересов. 


\section{Список литературы}

[1] Ю.Н. Вьюненко, Е.А. Хлопков, Г.А. Волков. В мон.: Перспективные материалы и технологии, под ред. В.В. Клубовича. (УО „ВГТУ“, Витебск, 2017) т. 1, с. 412.

[2] A.Yu. Kiselev, N.N. Belousov, E.A. Khlopkov, Y.N. Vyunenko. Mater. Res. Proceed., 9, 24 (2018).

DOI: http://dx.doi.org/10.21741/9781644900017-5

[3] С.П. Беляев, А.Е. Волков, В.А. Ермолаев, З.П. Каменцева, С.Л. Кузьмин, В.А. Лихачев, В.Ф. Мозгунов, А.И. Разов, Р.Ю. Хайров. Материалы с эфбектом памяти формы: Справ. изд., под. ред. В.А. Лихачева. (НИИХ СПбГУ, СПб., 1997-1998) в 4-х т.

[4] И.Н. Андронов, Р.А. Вербаховская, А.Н. Данилов, В.С. Корепанова. Заводская лаборатория, 76 (8), 38 (2010).

[5] J. Perkins, R.O. Sponholz. Metall. Trans., 15A (2), 313 (1984). DOI: $10.1007 / \mathrm{BF} 02645117$

[6] Y. Liu, Y. Liu, J. Van Humbeeck. Acta Mater., 47 (1), 199 (1998). DOI: 10.1016/S1359-6454(98)00325-5

[7] R. Lahoz, J.A. Puertolas. J. Alloys Compounds, 381, 130 (2004). DOI: 10.1016/j.jallcom.2004.03.080

[8] Z.G. Wang, X.T. Zu, X.D. Feng, S. Zhu, J.W. Bao, L.M. Wang. Mater. Design, 25 (8), 699 (2004). DOI: $10.1016 /$ j.matdes.2004.02.022

[9] W. Huang, W. Toh. J. Mater. Sci. Lett., 19, 1549 (2000). DOI: $10.1023 / \mathrm{A}: 1006721022185$

[10] Н.Г. Ларченкова, Е.Е. Тимофеева, А.Б. Тохметова, Е.Ю. Панченко, Ю.И. Чумляков. В сб.: Молодежкь, наука, технологии: новые идеи и перспективы, под ред. A.В. Цхе. (Том. гос. архит.-строит. ун-т, Томск, 2000) с. 68.

[11] Y.N. Vyunenko, L.F. Vyunenko, J. Physiq. IV (Proceedings), 112 (1), 235 (2003). DOI: 10.1051/jp4:2003873

[12] H. Scherngell, A.C. Kneissl. Scr. Metall., 39, 205 (1998). DOI: 10.1016/S1359- 6462(98)00155-9

[13] Г.А. Волков, Ю.Н. Вьюненко, Е.А. Хлопков. ФТВД, 29 (1), 78 (2019). 